\title{
Dynamic chlorophyll and nitrogen:carbon regulation in algae optimizes instantaneous growth rate
}

\author{
Kai W. Wirtz ${ }^{1, *}$, Markus Pahlow ${ }^{2}$ \\ ${ }^{1}$ Institute for Coastal Research, GKSS Research Centre, Max-Planck-Strasse 1, 21502 Geesthacht, Germany \\ ${ }^{2}$ Leibniz-Institut für Meereswissenschaften (IFM-GEOMAR), Düsternbrooker Weg 20, 24105 Kiel, Germany
}

\begin{abstract}
Photoacclimation models are a prerequisite for accurate estimates of primary production in aquatic environments under typically variable light conditions. They generally start from empirical functions of the internal chlorophyll a $(\mathrm{chl}$ a) or nutrient quota (e.g. the Droop model). We propose that physiological variations in phytoplankton reflect phenotypic adaptation which maximizes the growth rate. Growth maximization has to account for indirect effects of the enhancement of carbon (C) acquisition by acclimation, primarily through concomitant changes in the intracellular nitrogen (N) budget. Our model expresses, for the first time, the indirect effect of alterations in $\mathrm{N}$ uptake on $\mathrm{C}$ assimilation by a parameter-free trade-off between the 2 uptake functions. The model explicitly prescribes optimal protein partitioning between $\mathrm{N}$ and $\mathrm{C}$ uptake and sub-partitioning into carboxylation (1,5-bisphosphate carboxylase/oxygenase, Rubisco) and light harvesting. Applications to various published experimental data for different phytoplankton species support the validity of the optimality hypothesis and point to different flexibility in the re-organization of chloroplasts between taxa as well as to different time-scales on which photoacclimation operates. Simulations of a batch culture with the haptophyte Isochrysis galbana show that a decoupling in pigment $\mathrm{N}: \mathrm{C}$ from cellular $\mathrm{N}: \mathrm{C}$ may explain observed lag phases in chl a:C regulation. For diatoms, seemingly stronger constraints in intra-cellular stoichiometry determine the photoacclimative response to variable light regimes, as simulated and reported for Skeletonema costatum. N and chl a quotas correlate well in nutrientlimited chemostats of Thalassiosira fluviatilis, but in part decouple under light limitation. In N limited growth, non-linearity in $\mathrm{N}$ : C as expressed by the Droop function results from a combination of a linear quota dependency, down-regulation of relative carboxylation capacity, and increasing $\mathrm{N}$ costs of chl a synthesis at elevated growth rates. Our optimality assumption that includes indirect feedbacks through the concept of protein partitioning generates an accurate model for adaptation in physiological traits.
\end{abstract}

KEY WORDS: Photoacclimation - Trait-based model · Adaptive dynamics · Protein partitioning · Stoichiometry

Resale or republication not permitted without written consent of the publisher

\section{INTRODUCTION}

The way in which autotrophic organisms react to changing resource availability is largely determined by their physiological condition. This dependency on specific resource affinities and demands defines the physiological adaptive capacity of an algal cell. It underpins the ability to outgrow competitors under fluctuating light and nutrient levels (Walters 2005). Accordingly, during the course of evolution, photosynthetic microbes have developed efficient regulation strategies, among which, partitioning of energy or proteins into different metabolic or uptake functions is the most obvious (Richardson et al. 1983, Raven \& Geider 2003, Klausmeier et al. 2004). Variable resource allocation occurs across nutrient gradients and after changes in light (photoacclimation) (Litchman \& Klausmeier 2008). There is, in particular, considerable plasticity in the synthesis of light harvesting pigments, especially chlorophyll $a$ (chl a), together with their apoproteins (Sukenik et al. 1988, Prézelin et al. 1991). Photoacclimation by unicellular algal populations to short-term fluctuations like 
day-night cycles can be as pronounced as chl a:C ratio differences between different mutants, species or taxonomic groups (Sciandra et al. 1997, Anning et al. 2000, Suggett et al. 2007). Changes in cellular chl $a$ are typically concomitant with variations in internal element pools, including the most basic constituents, viz. nitrogen (N) and carbon (C). These $\mathrm{N}$ and $\mathrm{C}$ alterations may be best understood as the direct consequence of disproportionate rates of $\mathrm{N}$ and $\mathrm{C}$ uptake.

So far, the primary motivation for addressing photoacclimation and changes in element stoichiometry in a theoretical context has been to enhance model accuracy. Models with vertical resolution or with representation of nutrient limitation require a realistic calculation of photosynthesis by differently adapted phytoplankton (Cloern et al. 1995). With the resulting emphasis on 'how' N:C and chl $a$ :C ratios are regulated under variable light and nutrient conditions, the question of 'why' autotrophs have specific and regular response patterns in stoichiometry and physiology has received much less attention.

As a result, photoacclimation models generally use assumptions that are not explicable a priori. Many models start from the Droop model (Droop 1975), which is empirically derived (Flynn 2003), though a more mechanistic explanation was recently presented by Pahlow (2005). A widely accepted photoacclimation model was developed by Geider et al. (1998a) who proposed a tight coupling between $\mathrm{N}$ uptake rate and chl a synthesis. A modified version of the model of Geider et al. (1998a) explains short-term phenomena such as diel changes in $\mathrm{N}: \mathrm{C}$ and chl a:C ratios (Flynn et al. 2001). This coupling approach has limitations. For example, it does not resolve uncorrelated variations of $\mathrm{N}: \mathrm{C}$ and chl a:C ratios in some haptophytes (Flynn et al. 1994, Goericke \& Montoya 1998), especially during the initial lag phase in batch culture experiments (Smith \& Yamanaka 2007). Most importantly, Geider et al. (1998a) made clear that 'the model uses an arbitrary function to describe the relationship between $V_{\mathrm{m}}$ (maximum $\mathrm{N}$ uptake rate) and $\mathrm{N}: \mathrm{C}^{\prime}$ (p. 683). Zonneveld (1998) used similar assumptions to develop a cell stoichiometry model which is based on an overlay of 3 non-linear types of empirical quota dependencies in $\mathrm{N}$ acquisition.

The mechanistic gaps in these approaches reflect the persistent difficulty in integrating the 2-way interaction between cell physiology (quota) and metabolic functioning (uptake). In terrestrial ecology, a solution inspired by evolutionary thinking was put forward some 2 decades ago by e.g. Hilbert (1990), Friend (1991), and Hollinger (1996), who all put forward optimality arguments. Optimality offers an ecologically sound principle by which physiological variations may be described in mathematical terms. This concept is complementary to the recently formulated trait-based ecology (McGill et al. 2006, Litchman \& Klausmeier 2008); variations in a trait, also defining a functional niche, reflect phenotypic adaptation towards higher fitness (i.e. specific growth rate). At equilibrium, a trait value is optimal if the derivative of the fitness function with respect to the trait vanishes. As we also show below, this condition can be generalized to transitory trait variations (Wirtz 2000).

A major advantage of optimality-based models (given the fragmentary knowledge of mechanisms behind adaptations) is that they do not need to refer to complex descriptions of underlying processes at the cellular or molecular level. Nonetheless, these model approaches have received criticism (e.g. Agren 1996) and have had only limited acceptance, despite their high predictive power in several case studies (Wirtz 2002). One of their major weaknesses arises from the trade-off assumption in cost-benefit analysis. For any trait to be optimized, it is necessary to formulate benefits and costs. Both are, according to Richardson et al. (1983), equivalent to changes in net growth, $\mu$. Up to now, arbitrariness in the formulation of cost or trade-off functions has been high, as is the case for the quotadependency of $\mathrm{N}$ uptake, which is inherent in the models mentioned above. The argument applies equally to recent plankton models based on the same concept of growth optimization. An optimality argument was used by Finkel et al. (2004) for deriving size relationships in phytoplankton due to photoacclimation. This approach introduced a cost term for light-harvesting that, however, had no direct link to other ecophysiological functions, such as $\mathrm{N}$ uptake, although these functions are related to expenditures required by photosynthesis. Pahlow (2005) developed an accurate representation of a wide range of stoichiometric responses to changing light or external nitrogen level, using a similar cost term. This term is exclusively introduced for a consistent formulation of regulation in $\mathrm{N}$ uptake and chl a synthesis, but is not part of the metabolic functions defined in the model. In the optimal partitioning model formulated by Armstrong (2006), costs make up an explicit part of the photosynthesis function; nevertheless, the author still adopted the (nonmechanistic) quota dependency of $\mathrm{N}$ uptake introduced by Geider et al. (1998a). A frame combining down-regulation of $\mathrm{N}$ uptake and optimization of intracellular stoichiometry without ad hoc assumptions, therefore still awaits development.

The regulation model proposed here aims to predict the physiological response of photoautotrophs to variable environments by integrating mechanistic knowledge about $\mathrm{C}$ and $\mathrm{N}$ pathways with the optimality hypothesis. It resolves key traits that determine the conversion of electromagnetic to biochemical energy and of inorganic to organic material. These deter- 
minants are directly linked to protein partitioning. Their dynamics should describe an economically reasonable strategy to ensure that cells make the best use of their internal resources to cope (optimally) with changing environments. The model should provide a quantitative frame for testing the extent to which different phytoplankton species use optimality-seeking strategies. A consistent account of plasticity in physiological traits within models would, at the same time, refine our understanding of community adaptation in the same traits. When individual strains continually maximize carbon-based growth through photoacclimation and stoichiometric regulation, community changes will, with some delay, only occur in those functional traits that govern and constrain this optimization. In order to facilitate more general conclusions at the community level, we test the optimality approach using experimental data for different phytoplankton species responding to imposed variations in light and nutrient availability.

\section{MATERIALS AND METHODS}

$\mathbf{N}$ and $\mathbf{C}$ assimilation. We describe autotrophic biomass in units of particulate organic carbon (POC). Its relative change $\mu$ is determined by gross $C$-uptake rate $P$ and 2 loss terms.

$$
\frac{\mathrm{dPOC}}{\mathrm{d} t}=\mu \mathrm{POC} \text { with } \mu=P-\zeta V-L
$$

As explained in Appendix 1, exudation $L$ of dissolved organic material is a function of gross carbon fixation $P$. Carbon expenditures in nutrient uptake $V$ are quantified by the coefficient $\zeta$ that denotes the specific energy cost of N uptake. Such a linear relationship between N uptake and $\mathrm{C}$ respiration agrees well with empirical observations and theoretical knowledge of phytoplankton energy metabolism (Laws \& Wong 1978, Geider et al. 1998a, Pahlow 2005). Basic maintenance respiration is neglected in the growth equation, as we found it to be of minor importance for the regulation dynamics we studied. $\mathrm{N}$ uptake $V$ depends on the concentration of dissolved inorganic nitrogen (DIN) in the growth medium and will be defined later in Eq. (8). In a closed system, the DIN sink is presumed to be algal uptake alone, whereas the immediate transformation of phytoplankton organic matter losses (leakage) into inorganic forms acts as source. Leakaged material is assumed to have the same N:C stoichiometry (expressed by the quota $Q$ ) as POC.

$$
\frac{\mathrm{dDIN}}{\mathrm{d} t}=(L Q-V) \mathrm{POC}
$$

The temporal evolution of $Q$ is then determined simply by the imbalance between instantaneous $\mathrm{N}$ uptake and $\mathrm{N}$ demand for growth.

$$
\frac{\mathrm{d} Q}{\mathrm{~d} t}=V-(\mu+L) Q
$$

Light harvesting and photosynthesis. Cellular metabolism of photoautotrophs is fuelled by $\mathrm{C}$ assimilation through the photosynthetic Calvin cycle, the first step of which is controlled by the enzyme Rubisco (Ribulose-1,5-biphosphate carboxylase/oxygenase). Due to the high nitrogen stoichiometry of Rubisco and because $\mathrm{C}$ is delivered by photosynthesis itself, Rubisco synthesis is constrained primarily by the size of the free $\mathrm{N}$ pool. By 'free' we mean biochemically available, e.g. through transformation of existing biochemical compounds, or in the form of stored metabolites. In contrast, a residual fraction of $\mathrm{N}$ (expressed as $Q_{0}$ ) is assumed to be excluded from possible partitioning into $\mathrm{C}$ acquisition requirements. Thus, photosynthesis must rely on $Q-Q_{0}$ only. The function $q$ expresses the size of this free $\mathrm{N}$ pool normalized by its maximum $Q_{\max }-$ $Q_{0}$, following standard notation

$$
q=\frac{Q-Q_{0}}{Q_{\max }-Q_{0}}
$$

where $Q_{\max }$ is the maximum quota that can be maintained in the cell (Litchman et al. 2006). The condition $q \leq 1$ sets an upper constraint for the model variable $Q$. If $Q$ reaches $Q_{\max }, \mathrm{d} Q / \mathrm{d} t$ is set to zero and the uptake rate $V$ is lowered such that the balance in Eq. (3) is fulfilled.

To describe the regulation of Rubisco activity, we introduce the partitioning coefficient $f_{\mathrm{R}}$. This physiological trait variable expresses the relative pool size of free $\mathrm{N}$ invested into light-independent reactions, primarily those in the Calvin cycle (Friend 1991). Cells are remarkably plastic in the integration of a number of specific proteins and their prosthetic groups. This plasticity in $\mathrm{N}$ partitioning is very pronounced for Rubisco complexes which comprise the largest fraction of $\mathrm{N}$ within the chloroplast (Falkowski et al. 1989). Rubisco, in addition, controls the rate of $\mathrm{C}$ sequestration under saturating light by catalyzing the $\mathrm{CO}_{2}$ uptake within the first step of the Calvin cycle. Sukenik et al. (1987) and Geider et al. (1998a) gave independent evidence for a linear relationship between the ratio of Rubisco to the electron-transport chain and the maximal turnover rate of the photosynthetic apparatus. With this simple relation, the instantaneous $\mathrm{C}$ uptake $(P)$ reads as follows

$$
P=f_{\mathrm{R}} q \mu_{\mathrm{d}} u S
$$

Specific C-sequestration per unit of Rubisco activity comprises 3 factors for different rate limitations within the light reaction. First, maximal daily photosynthetic capacity $\mu_{\mathrm{d}}$ represents the highest possible (electron) turnover-rate of the 2 reaction centers (RCs) during daytime, and thus depends on the light:dark cycle 
duration. Since $\mu_{\mathrm{d}}$ is defined with respect to relative Rubisco activity $f_{\mathrm{R}} q$, which is usually $\ll 1$, its value may exceed classical estimates that range up to values around $4 \mathrm{~d}^{-1}$ (Finkel 2001) by nearly one order of magnitude. Following Marra (1978), the photoinhibition term $u$ denotes the relative concentration of undamaged D1 proteins in the RCs. The dependence of D1 protein damage and recovery on the $\mathrm{N}$ status $q$ and on photosynthetically active radiation (PAR) intensity are explained in Appendix 1. Finally, $P$ includes the normalized photosynthetic rate $S$, which is a measure of light-harvesting apparatus saturation. $S$ depends on the light intensity $I$ and $\theta$, the pigment concentration within chloroplasts (Pahlow 2005). Assuming that photon harvesting within the antenna follows Poisson statistics (Dubinsky et al. 1986) we have:

$$
S=1-\exp \left(-\alpha \theta I / \mu_{\mathrm{d}}\right)
$$

In this notation, the parameter $\alpha$ represents the light harvesting efficiency per unit of chloroplast pigment. To calculate the total cellular pigment concentration using the chloroplast-specific value $\theta$, it is necessary to quantify the relative chloroplast concentration, i.e. the ratio of chloroplast $\mathrm{C}$ to total cellular C. As a first postulate, this ratio should correlate with Rubisco, which forms a functional end-member of the RCs. However, there is ambiguity as to whether (1) the relative Rubisco Nfraction $f_{\mathrm{R}}$ (structural variable) or (2) the activity $f_{\mathrm{R}} q$ (functional variable) works as best proxy for relative chloroplast concentration. This ambiguity is mirrored by the different structural compositions as well as functioning of the photosystems between algal taxa (Guglielmi et al. 2005). In diatoms, for example, control of the Calvin cycle by the redox state of thiol groups and by Rubisco activase is absent, and so is a separation of grana thylakoids (rich in PS II) from stroma thylakoids with more PS I (Wilhelm et al. 2006). These differences affect the turnover ratio between the Calvin cycle and the remaining photosynthetic apparatus. We tentatively quantify the taxonomic variation in RC composition by the novel exponent $\sigma$ for the $\mathrm{N}$-quota dependence of relative chloroplast concentration, which is now written as the product $f_{\mathrm{R}} q^{\sigma}$. For diatoms with higher structural flexibility in the chloroplast compared to chlorophytes (Wilhelm et al. 2006), we assume an activity-related chloroplast density described by $\sigma=1$. Non-diatoms will have a smaller exponent $(\sigma=0)$, due to stronger structural constraints, which do not automatically allow for balancing of light reaction turnover rates and the Calvin cycle. With $\sigma=0$, relative carbon density of chloroplasts is given by $f_{\mathrm{R}}$ only, such that Rubisco activity $\left(f_{\mathrm{R}} q\right)$ decouples from chloroplast size.

$\mathbf{N}$ uptake. All carbon or energy not invested into the $\mathrm{C}$ acquisition machinery is assumed to feed into the pool responsible for nutrient uptake. Thus, $\mathrm{N}$ assi- milation directly competes for resources with the mechanisms for (1) light harvesting and (2) conversion of excitation energy into assimilation of inorganic C (electron chain and Calvin cycle). We assume that the $\mathrm{N}$ :C quota of compounds used for the light-independent reactions is the same as that for the proteins and enzymes used for $\mathrm{N}$ uptake. The relative fraction of $\mathrm{N}$ allocated to this pool, $f_{\mathrm{R}}$, will also determine the relative amount of $\mathrm{C}$ in the pool. In addition, $\mathrm{C}$ demand for light harvesting complexes (LHC) is expressed as the product of the chl $a: C$ ratio of the chloroplast, $\theta$, the relative density of the chloroplast, $f_{\mathrm{R}} q^{\sigma}$, and the $\mathrm{C}$ stoichiometry of pigment complexes. The latter, denoted as $\theta_{\mathrm{C}}$, was introduced in its inverse form by Geider et al. (1998a). However, the value of $\theta_{\mathrm{C}}$ stands for more than the elementary composition of chl a (and accessory carotenoids) since for each mole $\mathrm{C}$ in pigments, about 4 to 10 moles of $\mathrm{C}$ are bound to LHC, mostly as antenna proteins such as light-harvesting chlorophyll binding proteins Lhcp or Lhca2 (Six et al. 2008, Geider et al. 1998b, Falkowski et al. 1989). Therefore, the relative amount of C invested into LHC as given by $f_{\theta}$

$$
f_{\theta}=f_{\mathrm{R}} q^{\sigma} \theta / \theta_{\mathrm{C}}
$$

will be substantially higher than the 1 to $10 \%$ cellular $\mathrm{C}$ allocation to $\mathrm{chl} \mathrm{a}$ and other pigments (carotenoids) reported by Geider \& La Roche (2002). To sum up, the total $\mathrm{C}$ fraction reserved for photosynthesis is given by $f_{\mathrm{R}}+f_{\theta}$, and the remaining fraction is available for uptake sites and nutrient processing, constituting the internal control of $\mathrm{N}$ uptake rate $V$ :

$$
V=\left(1-f_{\mathrm{R}}-f_{\theta}\right)\left(V_{\mathrm{m}}^{-1}+(A \mathrm{DIN})^{-1}\right)^{-1}
$$

where $V_{\mathrm{m}}$ is the maximum acquisition rate and $A$ is the affinity.

While there is a linear quota dependency of photosynthesis $\left(f_{\mathrm{R}} q\right)$, the size of the free $\mathrm{N}$ pool does not affect $\mathrm{N}$ uptake. In this way, negative feedback of the $\mathrm{N}: \mathrm{C}$ ratio on $\mathrm{V}$-as reported by e.g. Goldman \& Glibert (1982), Parslow et al. (1984) or Morel (1987) is now explained as a response in protein partitioning. Proteins, however, consist of both C and N. Yet, $>90 \%$ of cellular nitrogen is allocated to proteins, as shown, for example, in N-starved cultures of Dunaliella tertiolecta by Dortch et al. (1984). We therefore suggest a prioritization scheme. Each uptake system preferentially uses newly gained resources for its own purposes. Only after subtraction of subsistence requirements will the remainder be transferred to other cellular pools. Prioritization is advantageous since it enables cells to escape a vicious cycle: under $\mathrm{N}$ depleted conditions, an uptake machinery that depends on the free $\mathrm{N}$-pool could not benefit from short $\mathrm{N}$ pulses, for example. There would be no free nitrogen left as needed to enhance assimilation rate. 
Table 1. List of model variables comprising traits $\left(f_{\mathrm{R}}, \theta\right), \mathrm{N}$ stoichiometry $(Q)$, and bulk concentrations in the medium (DIN, POC). Three model configurations are adopted to experiments with cultures of Thalassiosira fluviatilis $(\mathrm{Tf})$, Isochrysis galbana (Ig) and Skeletonema costatum (Sc). Initial values at simulation start for each configuration were taken from the experimental data. Starting Rubisco-N fractions $f_{\mathrm{R}}$ were estimated in the range 0.2 to 0.3 , which reflects intermediate values of the variability in simulated $f_{\mathrm{R}}$ for all 3 species

\begin{tabular}{|llcccc|}
\hline \multirow{2}{*}{ Symbol } & \multirow{2}{*}{ Description } & \multicolumn{3}{c}{ Initial values } & \multirow{2}{*}{ Units } \\
& & Tf & Ig & Sc & \\
\hline$f_{\mathrm{R}}$ & Relative N in Rubisco & 0.3 & 0.28 & 0.21 & - \\
$\theta$ & Chl a content in chloroplasts & 2.5 & 0.14 & 4.8 & $\mathrm{~g} \mathrm{chl} \mathrm{a} \mathrm{mol} \mathrm{C}^{-1}$ \\
$Q$ & N:C ratio & 0.09 & 0.04 & 0.16 & $\mathrm{~mol} \mathrm{~N} \mathrm{~mol} \mathrm{C}^{-1}$ \\
DIN & Dissolved inorganic nitrogen & 90 & 100 & 500 & $\mu \mathrm{M} \mathrm{N}$ \\
POC & Particulate organic carbon & 50 & 90 & 0.01 & $\mu \mathrm{M} \mathrm{C}$ \\
\hline
\end{tabular}

clearly exceed current quantitative or even qualitative knowledge of cellular biochemistry. Instead, we employ first principles for the dynamics of trait variables by translating the ability of cells to adjust to varying light and nutrient levels into an optimal allocation problem. In this way, cells are considered to be continually solving a distribution problem for internal resources.

Photosynthesis - and presumably photoacclimation-have evolved in both eukaryotes and prokaryotes over $10^{9}$ to $10^{12}$ generations. It is very likely that plasticity in these processes allows opti-

Adaptive dynamics. In our model, 2 major intrinsic variables directly regulate $\mathrm{C}$ and $\mathrm{N}$ acquisition by the cell. These physiological or trait variables are pigment content per chloroplast $\theta$ and $\mathrm{N}$ fraction in Rubisco $f_{\mathrm{R}}$ (Table 1 \& Fig. 1). We exclude the stoichiometric variable $Q$ from the list of regulating trait variables, since its dynamics directly follows from the imbalance equation. Quota variations are therefore a product and not a controlling factor of regulatory protein allocation in the cell. However, the time evolution of the 2 trait variables is not as easily formulated as that of $Q$. Mechanistically modeling the dynamics of the enzymerelated variable $f_{\mathrm{R}}$ or of the chl a build-up would require detailed knowledge of the various factors controlling gene expression, and the synthesis and decay of a large number of proteins. Assumptions needed for the vast array of non-linear reaction equations would

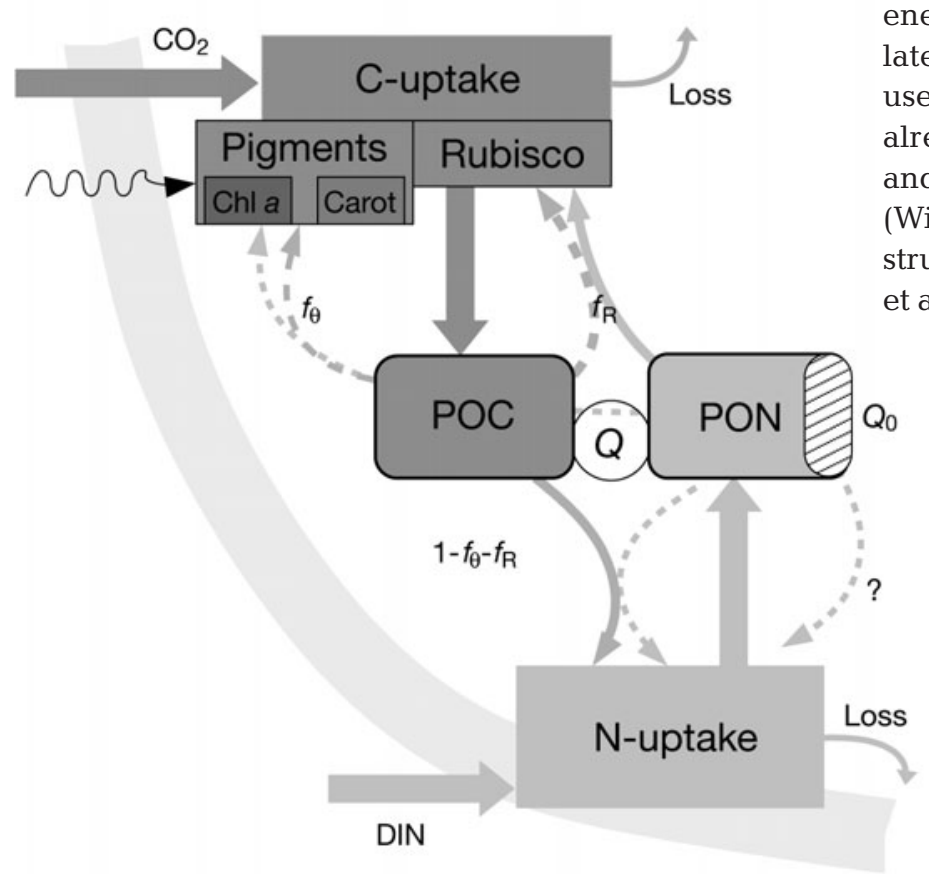

mal performance under a wide range of environmental conditions. In order to better understand the adaptive significance of photoacclimation, we postulate that variations in functional traits are fully adaptive in that they represent those strategies which enable maximal performance in terms of instantaneous growth. As soon as a potentially higher value in a trait variable leads to a rise in relative growth rate $(\mu)$, either selection will increase the population frequency of this higher value (if it is heritable) or gene expression will be regulated to achieve a higher value of the trait (if the latter is connected to functional proteins, for example). The concept implies that we do not deliberately differentiate between (genetic) adaptation and (physiological) acclimation insofar as both processes have the same ameliorating effect on instantaneous cell growth. Under this general assumption, pigment synthesis will occur only if it is beneficial for the entire energy budget of the cell. This behavior can be formulated using the adaptive dynamics approach, which is used in evolutionary models (Abrams 1999) and has already been applied to describe resource allocation and physiological regulation in plants and bacteria (Wirtz 2002, 2003), plankton population or community structure changes (Wirtz \& Eckhardt 1996, Fussmann et al. 2003) and - most related to this study - photosyn-
Fig. 1. Structure of the regulation model showing major processes and all model variables. Wavy arrow: irradiance, Carot: carotenoids. Unbalanced uptake of $\mathrm{N}$ and $\mathrm{C}$ leads to changes in the ratio between PON and POC $(Q)$. Intracellular $\mathrm{N}$ and $\mathrm{C}$ partitioning are described by the Rubisco: $\mathrm{N}$ ratio $\left(f_{\mathrm{R}}\right)$ and the chl a content in chloroplasts $\left(\theta\right.$, or $f_{\theta}$, respectively). Flows that are not explicitly resolved by the model, but follow from the internal mass balance, are displayed as dashed arrows 
thetic N-partitioning and photoacclimation in leaves of deciduous trees (Wirtz 2000).

$$
\frac{\mathrm{d} X}{\mathrm{~d} t}=\delta_{X} \frac{\mathrm{d} \mu}{\mathrm{d} X} \text { with } X=\theta, f_{\mathrm{R}}
$$

The adaptive dynamics links changes in traits to related gradients in growth rate $\mu$. Flexibility terms $\delta_{X}$ work as proportionality factors between 'forcing' gradients and adaptive response. They are formulated according to Wirtz \& Eckhardt (1996) and modified according to Wirtz (2002) so that $\delta_{\mathrm{R}}=\delta_{\mathrm{R}}^{\prime} f_{\mathrm{R}}\left(1-f_{\mathrm{R}}\right)$ and $\delta_{\theta}=\delta_{\theta}^{\prime} \theta\left(\theta_{\max }-\theta\right)$ with $\sigma_{\mathrm{R}}^{\prime} \approx \delta_{\theta}^{\prime} \approx 1$.

The total derivatives of $\mu$ in Eq. (9) include both the benefits and the costs of changing one of the traits. Under optimal conditions, total derivatives vanish and trait variables are fully acclimated.

One of the major bottlenecks of the optimization hypothesis, however, derives from our incomplete knowledge of total growth derivatives with respect to traits as defined above. While marginal benefits are completely described by partial derivatives $\partial \mu / \partial X$, which are mostly positive and can be calculated using Eqs. (1) to (5), marginal costs are, in general, not available beforehand. These costs follow from negative feedbacks or, more generally, trade-offs in the physiology, element budgeting and morphology of cells (Wirtz \& Eckhardt 1996, Wirtz 2002, Litchman \& Klausmeier 2008).

In this study, we derive a trade-off between $\mathrm{N}$ - and $\mathrm{C}$ uptake based on the balance equation (Eq. 3) only. Allocation of $\mathrm{N}$ to $\mathrm{C}$-uptake by increasing $f_{\mathrm{R}}$ will uplift carbon fixation $(P, E q .5)$ but, together with the concomitant increase in $f_{\theta}$ (Eq. 7) also lower $V$ (Eq. 8) and hence $q$, so that carbon fixation will decline. Conversely, allocation of $\mathrm{C}$ to $\mathrm{N}$ uptake by lowering $f_{\mathrm{R}}$ and $f_{\theta}$ will increase $q$ via a higher $V$ at the expense of reduced photosynthesis. The basic concept for quantifying these indirect costs lies in application of the product rule to combine marginal changes in the $\mathrm{N}$ status of the cell (induced by adaptive trait variations) with variations in photosynthetic rate that, in turn, follows those $\mathrm{N}$ quota changes. The first term, dependence of $Q$ on a trait $X$, reads in a differential form $\mathrm{d} Q / \mathrm{d} X$ such that we have:

$$
\frac{\mathrm{d} \mu}{\mathrm{d} X}=\frac{\partial \mu}{\partial X}+\frac{\partial \mu}{\partial Q} \cdot \frac{\mathrm{d} Q}{\mathrm{~d} X} \text { with } X=\theta, f_{\mathrm{R}}
$$

At steady state, the trade-off between $\mathrm{N}$ - and $\mathrm{C}$ uptake inherent to $\mathrm{d} Q / \mathrm{d} X$ is formalized by the balance equation (Eq. (3) with $\mathrm{d} Q / \mathrm{d} t=0$ ) and is here written in its implicit form:

$$
G(\mathbf{X}, Q)=V(\mathbf{X})-Q \mu^{\prime}(\mathbf{X}, Q)=0 \text { with } \mathbf{X}=\left\{\theta, f_{\mathrm{R}}\right\}
$$

$\mu^{\prime}$ is the rate of net growth that demands new nitrogen, thus $\mu^{\prime}=\mu+L=P-\zeta V$. Assuming a continuous $\mathrm{N}$ quota dynamics, the marginal variation $\mathrm{d} G$ will vanish, such that a small change in protein partitioning or, more generally, in the trait $X(\mathrm{~d} X)$ triggers a differential compensation in $Q(\mathrm{~d} Q)$. From the compensation, simple formulations for the derivatives $\mathrm{d} Q / \mathrm{d} \theta$ or $\mathrm{d} Q / \mathrm{d} f_{\mathrm{R}}$ arise:

$$
\begin{aligned}
\mathrm{d} G & =\frac{\partial G}{\partial X} \mathrm{~d} X+\frac{\partial G}{\partial Q} \mathrm{~d} Q=0 \\
& \rightarrow \frac{\mathrm{d} Q}{\mathrm{~d} X}=-\frac{\partial G}{\partial X}\left(\frac{\partial G}{\partial Q}\right)^{-1}=\left(\frac{\partial V}{\partial X}-Q \frac{\partial \mu^{\prime}}{\partial Q}\right)\left(\mu^{\prime}+Q \frac{\partial \mu^{\prime}}{\partial Q}\right)^{-1}
\end{aligned}
$$

The implicit derivation can obviously work only for $\partial G / \partial Q \neq 0$. The complementary case $(\partial G / \partial Q$ approaching zero) may, however, occur at low light intensity, especially under sudden perturbations, e.g. shortly after injection of the inoculum. To avoid numerical problems, the differential trade-offs $\mathrm{d} Q / \mathrm{d} X$ are therefore set to zero whenever a threshold is met $\left(|\partial G / \partial Q|<10^{-3} \mathrm{~d}^{-1}\right)$. Given the rarity of this situation, the exact value of the numerical threshold is found to minimally affect model outcomes.

Experimental data and parameterization. In order to obtain a representative picture of photoacclimative responses, the model was applied to 3 published studies. We chose the experiments of Laws \& Bannister (1980) with continuous cultures of Thalassiosira fluviatilis (Tf), Flynn et al. (1994) with a batch culture of Isochrysis galbana (Ig), and Anning et al. (2000) with a semi-continuous culture of Skeletonema costatum (Sc). With this selection, we aimed to cover nutrient and light limitation regimes, transitory and equilibrium responses, and diversity between algal species and taxa. Another criterion was to refer to data that were already used by modeling studies to facilitate comparison with alternative approaches. Original data underlying the work of Anning et al. (2000) were provided by R. Geider and N. Leonardos and were used in this study due to their high temporal resolution.

All strains of these studies were derived from culture collections, and illuminated by fluorescent lamps under a $12: 12 \mathrm{~h}$ light:dark cycle. Cultures were grown at $20^{\circ} \mathrm{C}$ (Tf), $18^{\circ} \mathrm{C}(\mathrm{Ig})$, and $15^{\circ} \mathrm{C}(\mathrm{Sc})$. The experiments also differed with respect to light intensity (Tf: see Fig. $2 \mathrm{C}$ for estimated values; Ig: $100 \mu \mathrm{mol}$ photons $\mathrm{m}^{-2} \mathrm{~s}^{-1}$; Sc: shift from 50 [low light, LL] to 1200 [high light, HL] and back to $50 \mu \mathrm{mol}$ photons $\mathrm{m}^{-2} \mathrm{~s}^{-1}$ after $5 \mathrm{~d}$ intervals), and nutrient concentrations in the reservoir or growth medium (Tf: $50 \mu \mathrm{M} \mathrm{NO}_{3}$ or $\mathrm{NH}_{4}$ under N-limitation, $250 \mu \mathrm{M} \mathrm{NO}_{3}$ under light limitation; If: $102 \mu \mathrm{M} \mathrm{NH}_{4} ;$ Sc: $500 \mu \mathrm{M} \mathrm{NO}_{3}$ ).

Light and nutrient conditions of the experiments were reproduced within 3 model configurations while temperature was not accounted for. The set-ups also differed with respect to parametrization (see Table 2). Values for $Q_{\max }$ were set according to measured N:C, for $\zeta$, following Pahlow (2005) and for $\sigma$ based on ecophysiological considerations (see 'Materials and methods: Light harvesting and photosynthesis'). Since N 
uptake affinity $A$, exudation ratio $\eta$, and specific flexibility in $\theta\left(\delta^{\prime}{ }_{\theta}\right)$ are poorly constrained by the available data, we used reasonable and species-independent values. PS II damage $\left(\mathrm{k}_{\mathrm{d}}^{\prime}\right)$ can only be calibrated in the Sc configuration. It will be stronger under natural conditions due to the higher UV irradiance in the solar spectrum as compared to that provided by the fluorescent tubes used in these experiments (W. Bilger pers. comm.). In the Ig set-up, $\delta^{\prime}{ }_{\theta}$ has to be raised to compensate for a low value of $\delta_{R}^{\prime}$, and exudation gains importance since DIN concentration would otherwise fall to unrealistically low values after the onset of N-limitation. The value assigned to $\eta$ is close to the estimates that follow from Tang \& Dam (2001). For each set-up, the remaining 6 parameter values $\left(\alpha, \delta_{\mathrm{R}}^{\prime}, \mu_{\mathrm{d}}, Q_{0}, \theta_{\mathrm{C}}\right.$, and $V_{\mathrm{m}}$ ) were calibrated using a systematic variation and a standard cost function which is the root mean square deviation between data and model outcomes, normalized by the variance in the data. Given the number of compared variables (Tf: 3, Ig: 4, Sc: 3), the degree of freedom for calibration is therefore relatively small.

\section{RESULTS}

\section{Stoichiometric response to $\mathrm{N}$-limitation}

The effects of DIN limitation on cellular stoichiometry have been documented in various experiments. Many of these refer to the Tf chemostat of Laws \& Bannister (1980). In this experiment, contents of nutrient-depleted cells had unequivocally increased $\mathrm{N}: \mathrm{C}, \mathrm{chl}$ a:C (Fig. 2) and chl a:N ratios (not shown, but inherent to the results obtained for $\mathrm{N}$ : $\mathrm{C}$ and chl $\mathrm{a}$ :C ratios) with increasing dilution rate and, as is clear from classical chemostat theory, also with increasing residual substrate in the medium. Model outcomes after parameter calibration reproduce the measurements of Laws \& Bannister (1980) with high accuracy. Chl a:C ratio in Tf converges towards zero at severe $\mathrm{N}$ depletion, while $\mathrm{N}$ : $\mathrm{C}$ ratio reaches a minimum value. An analogous behavior is observed for Ig within a transient batch set-up (Flynn et al. 1994). After DIN depletion at around Day 13, the chl a:C ratio starts to decrease (Fig. 3). In contrast to the steady state results for the diatom Tf, variations in chl a: $\mathrm{C}$ and $\mathrm{N}: \mathrm{C}$ ratios are decoupled in the haptophyte. Apart from a short period after the onset of $\mathrm{N}$ limitation, dynamics in $\mathrm{N}$ and chl a stoichiometry run independently both in the model and in the time series of Flynn et al. (1994). Down-regulation of $Q$ initiates shortly after inoculation (Days 6 to 7 ) when DIN is still fully available. This also means that cells best operate at high, but not maximal $\mathrm{N}: \mathrm{C}$ ratio, a finding supported by simulated equilibrium values for $\mathrm{N}: \mathrm{C}$ ratio of Tf which are much below the theoretical maximum $Q_{\max }$. In analogy to the down-regulation at high quota, Tf
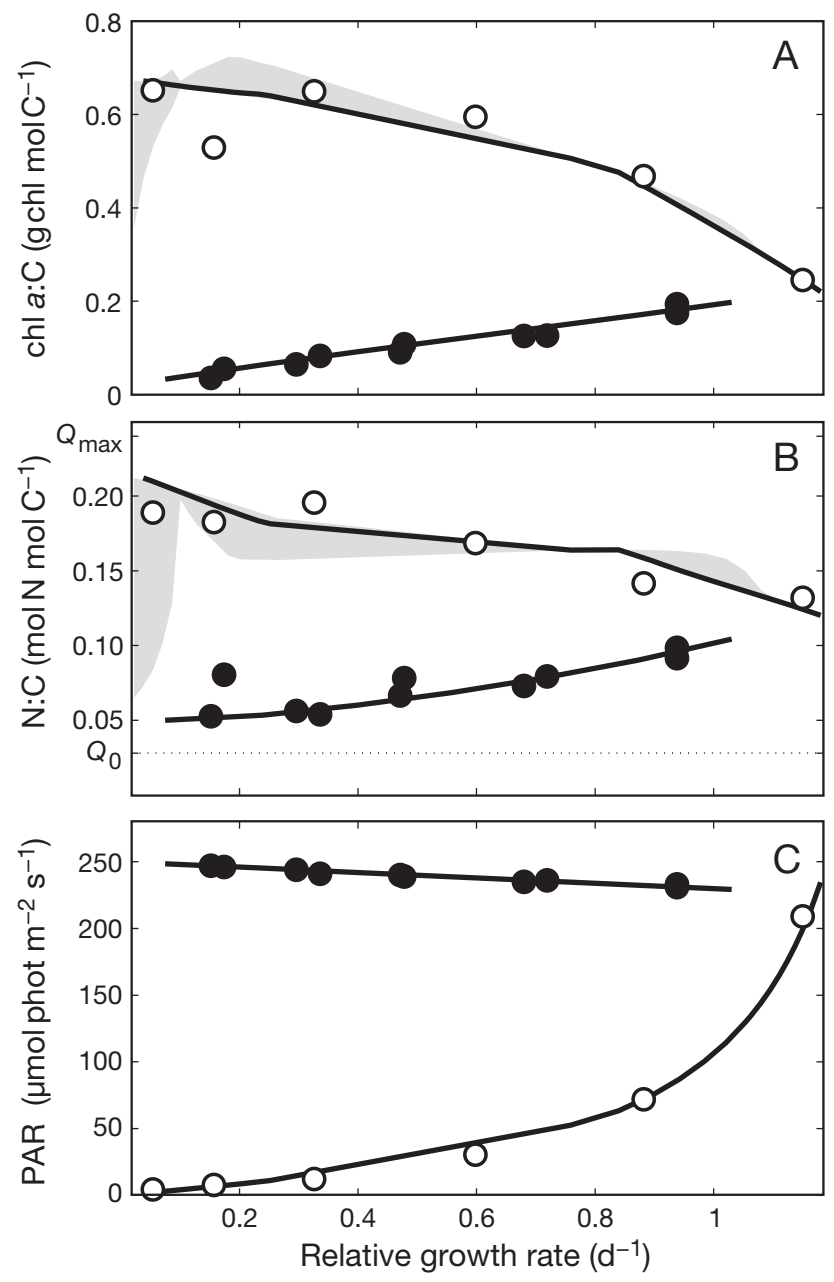

Fig. 2. Thalassiosira fluviatilis. Variations in (A) $f_{R} q \theta$ (chl a:C), (B) $Q(\mathrm{~N}: \mathrm{C})$ and $(\mathrm{C})$ light intensity with dilution rate in a light limited chemostat $(\mathrm{O})$ and a PAR saturated, N-limited experiment (๑). Circles are data of Laws \& Bannister (1980); solid lines are means of simulation results for Day 14. The intrinsic minimal quota $Q_{0}$ is added as a dotted line in (B). Gray areas show variability in daily means from Day 14 to the end of the simulation after $250 \mathrm{~d}$

and the haptophyte Ig reveal an apparent minimum quota that is more than double the intrinsic one $Q_{0}$ (cf. Figs. 2B, 3C \& 4).

During the phase of quota down-regulation in Ig, the slow rise in chl a:C ratio reflects a cell strategy to improve light harvesting, primarily through increasing chloroplast chlorophyll concentration $(\theta)$. High nitrogen costs of chl a synthesis slow down this process and are most important during the initial and final phases (relative control indices in Fig. 3). Rubisco becomes increasingly relevant before and during the start of $\mathrm{N}$ limitation. In a fully acclimated state, $\mathrm{N}$ partitioning into Rubisco balances $\mathrm{C}$ gain of carboxylation with associated $\mathrm{N}$ costs (converted to carbon gain units using $(\partial \mu / \partial Q) \cdot\left(\mathrm{d} Q / \mathrm{d} f_{\mathrm{R}}\right)$ in Eq. [10]). 

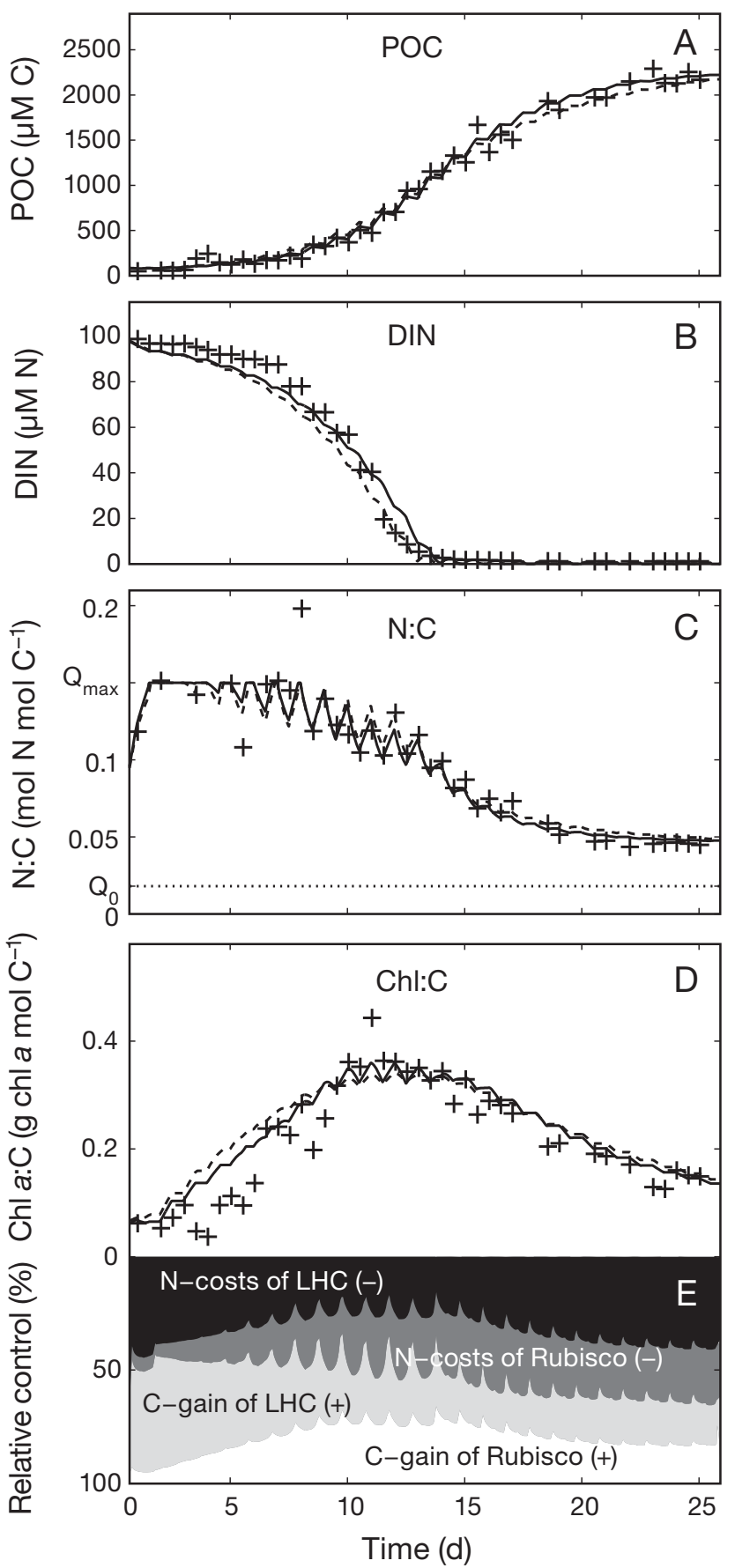

Fig. 3. Isochrysis galbana. Time evolution of (A) POC, (B) DIN, (C) N:C and (D) chl a:C $\left(f_{\mathrm{R}} \theta\right)$ in the batch experiment of Flynn et al. (1994). Observational data (crosses) are compared to 2 simulation runs, one with constant Rubisco fraction $f_{\mathrm{R}}$ (dashed line) and a fully adaptive version (continuous line) after a model spin-up of $12 \mathrm{~h}$. Differences in parameter values are given in Table 2. (E) Relative control indices for simulated $\mathrm{chl} a$ :C ratio variations. The indices quantify the strength of marginal 'economic forces' in chl a dynamics as given by Eq. (17) and calculated using Eq. (18), representing (1) C gain by carboxylation, (2) associated $\mathrm{N}$ costs, (3) C gain through light harvesting complexes (LHC) and (4) their $\mathrm{N}$ costs

\section{Photoacclimation}

Carbon-based $\mathrm{N}$ and chl a cell quotas of $\mathrm{Tf}$ reveal an intricate non-linear and time-dependent response when light limits growth instead of nutrients (Fig. 2). N quota under fully acclimated conditions is highest at intermediate PAR, slightly decreasing at higher growth irradiance. This relationship is in line with observations made with other species (Goldman 1988). In our model, it occurs when $\mathrm{N}$ demand of enhanced $\mathrm{C}$ uptake exceeds supply by nutrient uptake machinery, even at saturating DIN concentration. N quota at low growth rate is much less constrained and is a function of acclimation time. The model parameter set (Table 2) is calibrated to reproduce measured stoichiometry after about $20 \mathrm{~d}$, since in this period simulated biomass and nutrient concentration varied very little. This situation corresponds to the 'steady state' condition in most chemostats. However, continuous cellular adaptation at low dilution rates leads to biomass accumulation after many months, with consecutive depletion of DIN and decline in N:C and chl $a$ :C ratios. Hence, the gray areas in Fig. 2 indicate effects of maintained evolution of internal variables over longer timescales. Typical photoacclimation with lower chl a:C ratio at higher light intensities is, instead, quickly established in the simulation and then becomes constant over time. Increased relevance of Calvin cycle activity is responsible for higher $f_{\mathrm{R}}$ (cf. Fig. 7), while a lower importance of LHC leads to a considerable reduction of chl $a$ in chloroplasts.

In dynamic environments, stoichiometric adaptation is expressed as nighttime $\mathrm{N}: \mathrm{C}$ and chl a:C ratio increases over daytime values. Diurnal cycling amplitude can be as large as mid-term acclimation after changing daytime PAR by $>1$ order of magnitude (Anning et al. 2000). Our model not only fits average stoichiometry changes under alternating low and high PAR regimes (LL and HL), but also precisely redraws the diurnal variability as evident in Fig. 5. Both shortand mid-term responses to variable irradiance are equally 'forced' in the model by the same growth derivatives with respect to the traits $f_{R}$ and $\theta$. At night, chl a:C ratio dynamics are strongly connected to the cellular $\mathrm{N}$ status due to the linear dependence of chl a:C ratio on $q$ ( $\sigma=1$ for diatoms), while adaptations in $f_{\mathrm{R}}$ and $\theta$ become negligible. This can be directly inferred from the low-pass filtered control indices in Fig. 5. During daytime under a LL regime, $\mathrm{N}$ demand and C gain of LHC prevail over those of Rubisco. The relevance of LHC disappears in HL. Reallocation of N from LHC to Rubisco and nutrient uptake together with a sudden drop in total proteins $(q)$ then leads to a down-shift in chl a:C with subsequent day-night oscillations. The role of LHC for cellular carbon economy 
Table 2. List of model parameters and auxiliary variables (without values). The different parameter sets correspond to the 3 model configurations (for abbreviations, see Table 1). LHC: light-harvesting complex. Values in parentheses are re-calibrated values for alternative configurations where $f_{R}$ dynamics is switched off

\begin{tabular}{|c|c|c|c|c|c|}
\hline \multirow[t]{2}{*}{ Symbol } & \multirow[t]{2}{*}{ Description } & \multicolumn{3}{|c|}{ - Value } & \multirow[t]{2}{*}{ Unit } \\
\hline & & $\mathrm{Tf}$ & Ig & Sc & \\
\hline$A$ & Affinity to inorganic $\mathrm{N}$ & 25 & 25 & 25 & $\mathrm{~m}^{3}(\mathrm{~mol} \mathrm{C} \mathrm{d})^{-1}$ \\
\hline$\alpha$ & Specific light absorption & 0.12 & $0.07(0.06)$ & $0.045(0.043)$ & $\mathrm{m}^{2}$ mol C $(\mu \mathrm{mol} \text { photons g chl } a)^{-1}$ \\
\hline$\delta_{\mathrm{R}}^{\prime}$ & Specific flexibility in $f_{\mathrm{R}}$ & 1 & $0.35(0)$ & $0.5(0)$ & - \\
\hline$\delta_{\theta}^{\prime}$ & Specific flexibility in $\theta$ & 1 & 1.7 & $1(1.3)$ & - \\
\hline$\eta$ & Exudation vs. production ratio & 0.01 & 0.053 & 0.09 & - \\
\hline$f_{\theta}$ & Relative C in LHC & & & & - \\
\hline$I$ & Photon flux & & & & $\mu \mathrm{mol}$ photons $\mathrm{m}^{-2} \mathrm{~d}^{-1}$ \\
\hline$k_{\mathrm{r}}$ & Protein D1 recovery rate & & & & $d^{-1}$ \\
\hline$k_{\mathrm{d}}$ & Protein D1 damage rate & & & & $d^{-1}$ \\
\hline$k_{\mathrm{d}}^{\prime}$ & Chlorophyll-specific D1 damage & 0.4 & 1.5 & 0.7 & $\mathrm{molC}^{2} \mathrm{~g} \mathrm{chl} a^{-2}$ \\
\hline$L$ & Exudation rate & & & & $d^{-1}$ \\
\hline$\mu$ & Relative growth rate (RGR) & & & & $d^{-1}$ \\
\hline$\mu_{\mathrm{d}}$ & Potential production $\left(f_{\mathrm{R}} q=1\right)$ & 26 & $4.5(5.5)$ & $24(29)$ & $\mathrm{d}^{-1}$ \\
\hline$P$ & Gross C uptake rate & & & & $\mathrm{d}^{-1}$ \\
\hline$q$ & Relative size of the free $\mathrm{N}$ pool & & & & - \\
\hline$Q_{0}$ & Minimal N:C & 0.03 & $0.018(0.014)$ & $0.043(0.04)$ & $\operatorname{molN} \mathrm{molC}^{-1}$ \\
\hline$Q_{\max }$ & Maximal N:C & 0.24 & 0.15 & 0.18 & $\mathrm{molN} \mathrm{molC}^{-1}$ \\
\hline$\sigma$ & $\begin{array}{l}\text { N-quota dependence of } \\
\text { chloroplast concentration }\end{array}$ & 1 & 0 & 1 & - \\
\hline$S$ & Light response curve & & & & - \\
\hline$\theta_{\mathrm{C}}$ & Inverse C stoichiometry of LHC & 1 & 1.1 & $5(4.4)$ & gchl a molC ${ }^{-1}$ \\
\hline$u$ & Photoinhibition factor & & & & - \\
\hline$V$ & $\mathrm{~N}$ uptake rate per unit carbon & & & & $\operatorname{molN}(\operatorname{molC~d})^{-1}$ \\
\hline$V_{\mathrm{m}}$ & Maximal $\mathrm{N}$ uptake rate & 2.1 & 0.14 & 0.3 & $\operatorname{molN}(\mathrm{molC} \mathrm{d})^{-1}$ \\
\hline$\zeta$ & Respiratory $\mathrm{C}$ cost of $\mathrm{N}$ uptake & 2.3 & 2.3 & 2.3 & $\operatorname{molC~} \mathrm{molN}^{-1}$ \\
\hline
\end{tabular}

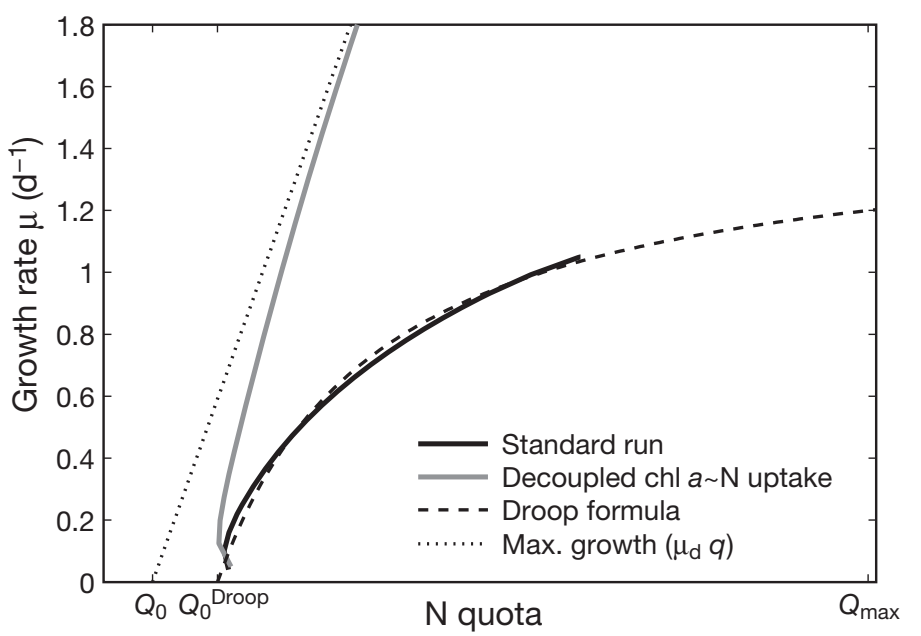

Fig. 4. Relative growth rate dependence on internal N quota. Steady state results are shown for the standard Thalassiosira fluviatilis parametrization (black line) and a version where chlorophyll synthesis is decoupled from construction of uptake sites (gray line, $f_{\theta}=0$, realized by $\theta_{\mathrm{C}}=1000 \mathrm{gchl} a$ $\mathrm{molC}^{-1}$. For comparison, the Droop function is plotted (dashed line, $1.5 \mathrm{~d}^{-1}\left(1-Q_{0}{ }^{\mathrm{D}} / Q\right.$ ), with $Q_{0}{ }^{\mathrm{D}}=0.05 \mathrm{molN}$ mol $\mathrm{C}^{-1}$ ). The linear function $\mu_{\mathrm{d}} q$, which in the model expresses the maximal capacity for biosynthesis, is multiplied by a factor of $0.5^{2}$ to reflect the $12: 12 \mathrm{~h}$ light:dark cycle and the fact that $f_{\mathrm{R}}$ is about 0.5 in this experiment (dotted line at left) is re-established after switching to LL again. The induced response in the simulated chl a: $\mathrm{C}$ ratio turns out to be as fast as the $\mathrm{N}: \mathrm{C}$ ratio recovery. The latter overestimates the observed $\mathrm{N}$ quota levels which, however, are far lower than in the initial LL period. The model is able to reproduce an adaptation period in the chl a:C ratio with intermediate values and lowamplitude day-night cycles. Also, changes in control indices during Days 10 to 15 indicate that cells have not reached internal equilibrium after several days. Hence, as the 2 earlier case studies have shown, understanding cellular adaptation requires a mid- to long-term duration of in silico and in vitro experiments on the scale of weeks or months.

As a test of the photosynthetic functions employed by the model, we compared measurements of maximal photosynthetic capacity with calculated values (Fig. 6). Despite the high frequency variability, both match surprisingly well. Two largely differing $P-I$ curves obtained in the LL and HL regimes are fitted with high accuracy. This includes the relatively elevated effect of photo-inhibition at high PAR for cells acclimated to LL. In contrast to usual fitting procedures, the coefficients (e.g. $P_{\max }, \alpha$ ) have not been calibrated here. They derive instead from the simulated adaptation of internal traits $f_{\mathrm{R}}$ and $\theta$. 

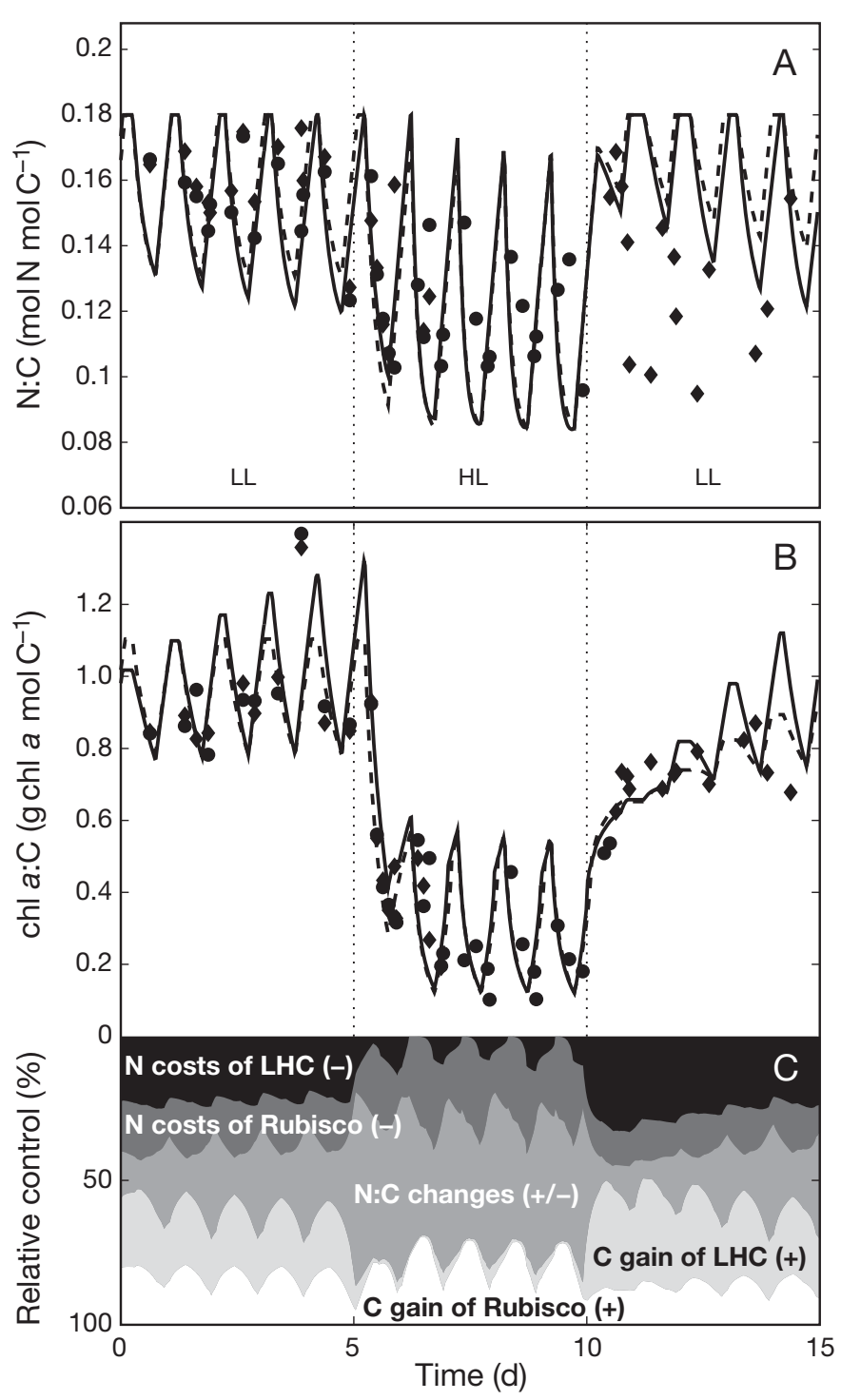

Fig. 5. Skeletonema costatum. Stoichiometric dynamics of (A) cellular nitrogen $(Q)$ and $(\mathrm{B}) \mathrm{chl}$ a $\left(f_{\mathrm{R}} q \theta\right)$. Light is shifted from low (LL) to high (HL) intensity and, after $5 \mathrm{~d}$, to LL again. Experimental data from 2 parallel experiments $(\bullet \bullet)$ of Anning et al. (2000) (values with higher temporal resolution from R. Geider unpubl.) are compared to 2 simulation runs. One simulation was run with constant Rubisco-N fraction $f_{\mathrm{R}}$ (dashed line), the second one with a fully adaptive set-up (continuous line). Differences in parameter values are given in Table 2. A model pre-run of $7 \mathrm{~d}$ is not shown. (C) Relative control index of chl a:C ratio variations, analogous to Fig. 3

\section{Adaptation configurations}

How many trait variables are needed to cope with the physiological adaptation of algae to varying nutrient and PAR levels? We addressed this question by comparing 2 different model configurations, one without Rubisco dynamics $\left(\delta_{\mathrm{R}}^{\prime}=0\right)$ and the second in the fully adaptive standard version. In the nutrient-limited (as in the PAR-limited) case, differences between configurations are negligible for the entire set of state variables following recalibration of few parameters (Fig. 3, cf. Table 2). Only diurnal fluctuations in the Sc set-up are slightly better resolved when $f_{\mathrm{R}}$ adaptation is effective (Fig. 5).

\section{Protein partitioning and pigment composition}

How the adaptation model works can be best understood by tracing the partitioning of proteins to the 2
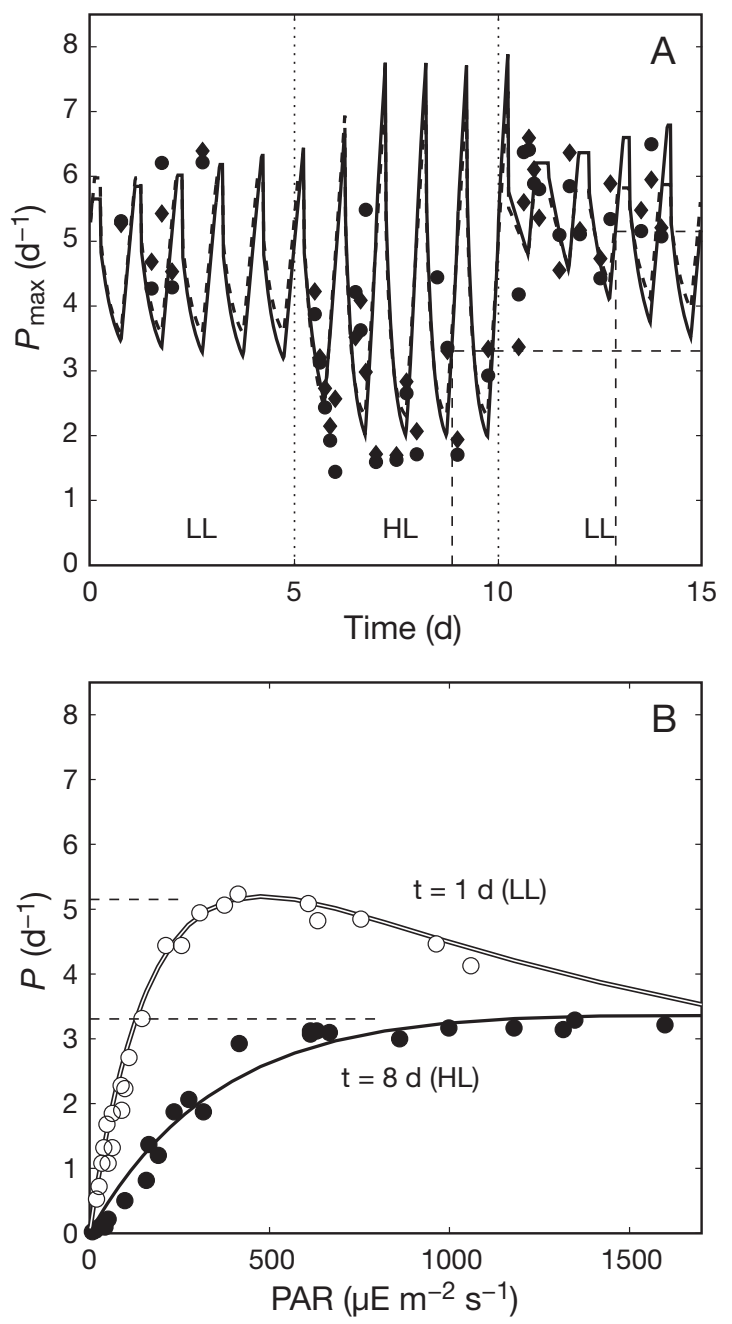

Fig. 6. Skeletonema costatum. (A) Time course of maximal photosynthetic capacity $\left(P_{\max }=\max _{I}\{P(I)\}\right)$. Experimental data originate from Anning et al. (2000), complemented by R. Geider and N. Leonardos (unpubl.). The 2 regulation configurations are described in Figs. 3 \& 5. Straight dashed lines mark timing and maximal value of individual $P$ - $I$ measurements. (B) Photosynthetic rates as a function of PAR. P-I curves measured by Anning et al. (2000) are compared with instantaneous C uptake rates calculated using Eq. (5) 


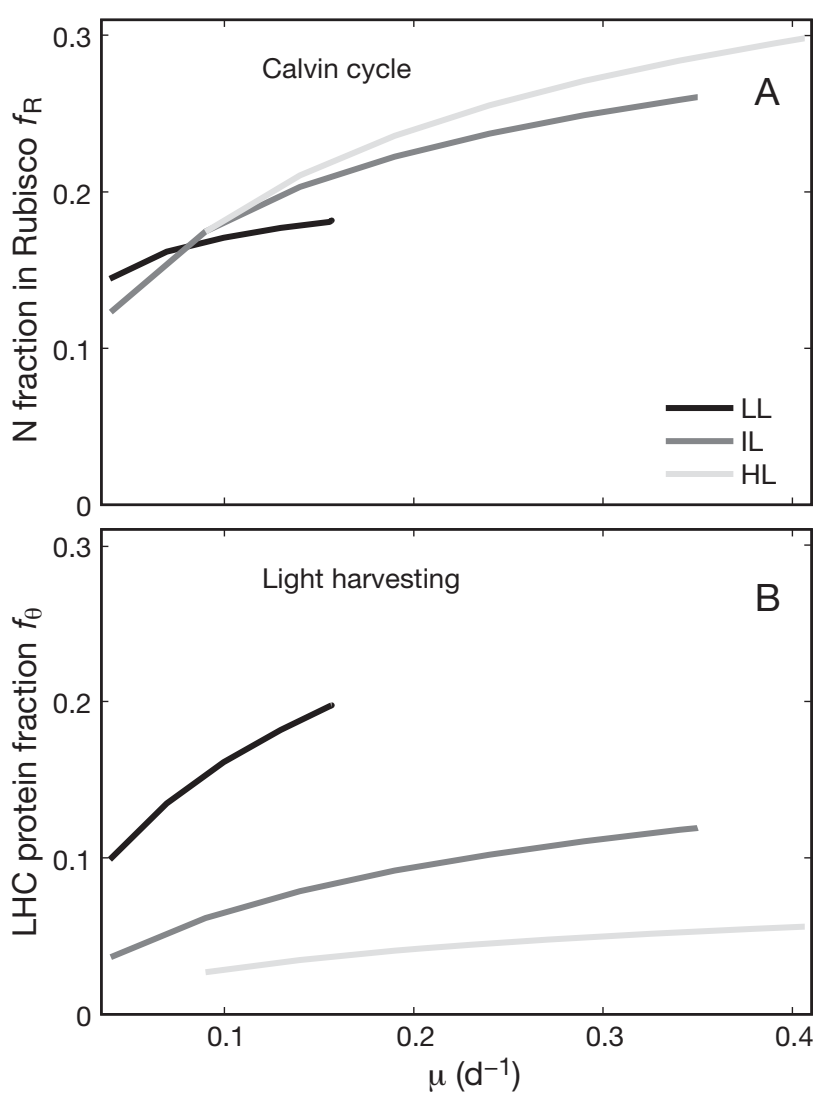

Fig. 7. Protein partitioning over growth rate in N-limited chemostat (Isochrysis galbana). (A) Rubisco-N fraction of total cellular $\mathrm{N}\left(f_{\mathrm{R}}\right)$ computed for low, intermediate and high PAR. LL: $30 \mu \mathrm{mol}$ photons $\mathrm{m}^{-2} \mathrm{~s}^{-1}$; IL: $175 \mu \mathrm{mol}$ photons $\mathrm{m}^{-2} \mathrm{~s}^{-1}$, corresponding to the experiment of Falkowski et al. (1989); HL: $500 \mu \mathrm{mol}$ photons $\mathrm{m}^{-2} \mathrm{~s}^{-1}$. Parametrization identical to I. galbana set-up. (B) corresponding carbon fraction of the light harvesting complexes $f_{\theta}$ most central photosynthetic functions, carboxylation $\left(f_{\mathrm{R}}\right)$ and light harvesting $\left(f_{\theta}\right)$. As shown in Fig. 7, carboxylation in $\mathrm{Ig}$ is up-regulated at higher PAR in contrast to LHC. Both $f_{\mathrm{R}}$ and $f_{\theta}$ increase with growing dilution rate in the simulated chemostats. The sensitivity of partitioning to growth rate, however, depends on the light level. $f_{\theta}$ is most sensitive under LL whereas $f_{\mathrm{R}}$ is rather constant.

The calculated partitioning of photosynthetic proteins is central not only to analysis of autotrophic regulative responses to variable environments; our model indicates that variable protein fractions can also be used as proxies for changes in the spectral properties of cells. This can be inferred from Fig. 8, which shows the time course of Ig pigment composition (carotenoids:C ratio) measured by Flynn et al. (1994). The ratio gently changes during the course of $\mathrm{N}$ limitation. A comparison with the temporal evolution in the simulated $\mathrm{N}$ fraction in Rubisco $f_{\mathrm{R}}$ suggests a correlation between the 2 quantities.

\section{DISCUSSION}

\section{Optimality in key physiological traits}

The reference data we used for model validation include various irregular dynamic patterns of physiological variables in addition to bulk POC, DIN or photosynthesis measurements. Despite this richness, quantitative agreement between model results and observations is very high, which supports our starting model hypothesis that variations in physiological variables maximize carbon-based growth of the whole cell. Since the adaptive dynamics framework has no mechanistic reference to phenotype acclimation and ignores delays in biosynthesis due to intermediate metabolites or finite rate of signal transduction, quantitative matching between model results and observations would not be expected, in particular, for transitory dynamics including lag effects. Growth optimization thus appears as a continuous objective during reorganization of cellular physiology.

This 'goal-oriented' approach (sensu the Aristotelian view of natural processes) leads to meaningful interpretations since regulation phenomena can be understood in an evolutionary context. Light and nutrients make photoautotrophs grow, and continual fluctuations in both trigger the second fundamental biological process, which is adaptation. Adaptation operates on many levels of organization (cells, genes,
Fig. 8. Isochrysis galbana. Temporal variation in the ratio of total carotenoids (scaled) to cellular carbon (from Flynn et al. 1994) compared to the chl a content of chloroplast $(\theta)$ simulated by the model 
communities) that, in turn, undergo dynamic transformations on different time scales. In the case of photoacclimation, this means that cells not only respond to forces of selection by evolving the bestadapted physiology for a specific nutrient and light environment, but also by evolving the ability to instantly adjust their physiology whenever necessary. Both processes, selection for physiological traits and selection for physiological plasticity are governed by the same fitness function, i.e. relative growth rate. The 2 adaptations are also mutually dependent. Photoacclimation will delay community changes because the ability of individual species or strains to cope with varying light conditions dampens shifts between species. Species shifts, in turn, will primarily work on those functional traits that govern and constrain acclimation. In our model frame, these are, for example, specific light absorption $(\alpha)$ and $C$ stoichiometry of LHC $\left(\theta_{\mathrm{C}}{ }^{-1}\right)$. Their intra-specific variation turns out to be correlated after calibration. One would indeed expect higher absorption capabilities from a more costly LHC. Minimal $\mathrm{N}: \mathrm{C}\left(Q_{0}\right)$, and maximal $\mathrm{N}$ and $\mathrm{C}$ uptake rate $\left(V_{\mathrm{m}}, \mu_{\mathrm{d}}\right)$, are highly effective and variable functional traits allowing one to track community changes triggered by variations in light and nutrient availability (Litchman et al. 2006).

Litchman \& Klausmeier (2008) also listed a variety of (morphological) trade-offs guiding phytoplankton adaptation at the community level. In this study we derived a physiological trade-off that converts effects of trait variations on $\mathrm{C}$ uptake as well as indirect effects through the cellular $\mathrm{N}$ budget into the same currency. Our approach leads to a parameter-free estimate of the marginal $\mathrm{C}$ gain of $\mathrm{N}$ uptake $V$ (Eqs. 10 $\& 12$ ) by simply making use of the balanced growth equation. Synthesis of chl a is then linked to the cellular $\mathrm{N}$ and $\mathrm{C}$ cycle only through protein partitioning (cf. explicit dependencies of $P$ and $V$ on $f_{\mathrm{R}}$ and $f_{\theta}$ ). By mutually dependent adaptation in the partitioning coefficients $f_{\mathrm{R}}$ and $f_{\theta}$, variations in $\mathrm{N}: \mathrm{C}$ and chl a:C ratios become formally de-coupled, even though not functionally independent. Cells lower their chl a:C ratio either after the onset of N-limitation, or after an increase in irradiance. To this end, they employ a limited repertoire of mechanisms, such as dilution through growth, or expression of chlorophyllase. But the teleological reason for the same kind of response may be different, as illustrated by the relative control indices for chl a:C ratio dynamics. While under nutrient limitation the high amount of $\mathrm{N}$ bound in Rubisco can be re-invested into $\mathrm{N}$ uptake with much more carbon return, the competitive role of Rubisco in the PAR shift experiment is more limited to diel changes in the chl a:C ratio. The highest contribution for the rapid decline in chlorophyll derives from changes in the $\mathrm{N}: \mathrm{C}$ ratio. The latter reflects the imbalance after increasing $\mathrm{C}$-uptake with only moderate ability of the cell to raise $\mathrm{N}$ uptake accordingly.

Most simulation results can be equally produced using either a constant or a variable Rubisco-N ratio $f_{\mathrm{R}}$. The reasons why we resolve this 'luxury' variable, apparently violating Occam's parsimony principle, are 3-fold. (1) Variations in $f_{\mathrm{R}}$ do exist, as discussed below, and might serve as a further model constraint. (2) The additional model complexity comes at extremely low parameterization costs. Finally, a larger set of trait variables can help to trace changes in optical absorption properties during photoacclimation. For example, the correlation between photosynthetic protein partitioning and the carotenoids: $\mathrm{C}$ ratio only arises in the fully adaptive model version. When nitrogen is to be allocated into enzymes like Rubisco or into uptake apparatus, it is advantageous to make use of nonchlorophyllous pigments. Preference for carotenoid synthesis or chlorophyll decay under $\mathrm{N}$ limitation is motivated by relatively low $\mathrm{N}$ costs of carotenoid rich pigments compared to chl a (Falkowski et al. 1989, Herzig \& Falkowski 1989, Berges et al. 1996). Following this strategy, however, is not as effective as merely reducing chl $a$, as is obvious from the much stronger variation in the chl a:C ratio during the experiment (cf. Figs. $8 \& 3$ ).

\section{Differential $\mathbf{C}$ and $\mathbf{N}$ partitioning}

Under $\mathrm{N}$ limitation, the concentration of Rubisco as well as the ratio of Rubisco activity to electron transport activity declines (Berges et al. 1996, Evans \& Terashima 1987, Sciandra et al. 1997). The first process can be understood as a mere consequence of lower intracellular nitrogen, while the ratio decline (accompanied by a decrease in $f_{\mathrm{R}}$ ) is due to the previously mentioned higher economic revenue of Rubisco $\mathrm{N}$ when re-allocated to $\mathrm{N}$ uptake. In the chlorophyte Dunaliella tertiolecta under N limitation, Geider et al. (1998b) found rather robust Lhcp levels in contrast to much more sensitive reactions of Rubisco. A similar phenomenon has been reported by Falkowski et al. (1989) for Ig and for a cryptophycean by Rhiel et al. (1986). Robustness in $f_{\theta}$, together with sensitivity of $f_{\mathrm{R}}$ under intermediate to high PAR, can to some extent be reproduced by the model. The range of simulated $f_{\mathrm{R}}$ in Ig precisely matches the range of 0.12 to 0.24 found by Falkowski et al. (1989) at intermediate PAR. However, the calculated increase in $f_{\theta}$ at higher growth rates exceeds the narrow interval of 0.06 to 0.08 reported in the study (Falkowski et al. 1989). Different sensitivities in protein partitioning follow from the fact that, in the model, $f_{\mathrm{R}}$ greatly exceeds $f_{\theta}$ under high PAR. When 
forced to reduce $\mathrm{N}$ expenses, cells react most effectively through reducing their carboxylation capacity in the form of N-rich Rubisco.

The assumed difference between diatoms and nondiatoms (at least haptophytes) through the parameter $\sigma$ was a prerequisite for simulating 2 different types of correlation between the chl $a: C$ and $\mathrm{N}: \mathrm{C}$ ratios. Observed co-variations (see Sc) and their absence (Ig) have been linked to a taxonomic divergence in photosystem composition. Compositional differences lead to distinct stoichiometric ratios between complexes sustaining light-dependent and light-independent reactions. Some further evidence supports this notion. In non-siliceous species, decoupling chloroplast density from Rubisco activity induces a higher sensitivity of simulated Rubisco levels to nutrient limitation compared to diatoms (Falkowski et al. 1989, Geider et al. 1993). A more apparent indicator for the decoupling is the convergence behavior of the chl $a$ :C ratio when $\mathrm{N}$ becomes depleted. While Sakshaug et al. (1989) found near-zero chlorophyll levels at low dilution rates in a Sc chemostat, Goericke \& Montoya (1998) observed a minimum of $0.2 \mathrm{pgchl}$ a per cell in the 2 haptophytes Ig and Pavlova lutheri.

\section{Implications for laboratory studies}

All our simulation studies demonstrate that cells require a relatively long period to reach internal equilibrium. Acclimation takes place far beyond the onset of a 'steady-state' that is classically defined in terms of biomass and growth variations. In the literature, there is still a tendency to undervalue transient effects, which can bias the interpretation of results. For example, differences in photoadaptation from HL to LL and from LL to HL found by Prézelin et al. (1991) may in part reflect under-estimated acclimation periods. We thus emphasize the relevance of specifying the pre-conditioning of cultures in great detail, including the time schedule of preparation. Simulations of Ig growing in batch culture are indeed sensitive to the initial values of internal variables $\theta$ and $f_{\mathrm{R}}$. Relatively low starting values prevent strong increases in growth rate since small values in $\mu$ lead to high differential $\mathrm{N}$-costs of chl a synthesis, as expressed by $\mathrm{d} Q / \mathrm{d} \theta$ (Eqs. $10 \& 12$ ).

Our dynamic simulations revealed that transient data are also highly effective in constraining the parametrization of the model. We in particular suggest that switching light experiments similar to the one conducted by Anning et al. (2000) could be used to test the model for different species like diatoms of different cell sizes or a green algae.

In future studies, the model assumptions that the photoacclimative response (1) is ruled by intracellular optimization, and, more specifically, (2) is mediated by protein partitioning should be better connected to direct observations. The mere number of (in part unknown) proteins involved in photosynthesis and nutrient uptake, their high turnover rate and limits to analytical accuracy still challenge a quantitative assessment.

\section{Implications for modeling}

With the optimality approach proposed here, we seek to replace-or to better understand-empirical formulations using cause-effect assumptions (Anderson 2005). A central example is the Droop-like nonlinear N-quota dependency of growth in Fig. 4 which arises from a combination of (1) linear cause-effect relations, (2) down-regulation of relative carboxylation capacity at low $Q$, and (3) increasing $\mathrm{N}$ costs of chl a synthesis at high $\mu$. Acclimated $N$ quota, as a consequence, also by far exceeds $Q_{0}$. Under $\mathrm{N}$ replete conditions, $\mathrm{N}$ quota is almost always maintained much below its upper bound $Q_{\max }$. Insensitivity to physiological or physico-chemical boundaries is again reasonable in an evolutionary context, since cells with lower subsistence demand or more storage capability would have a strong competitive advantage.

An efficient way for maintaining $\mathrm{N}$ quota much below its (non-optimal) upper bound $Q_{\max }$ is exudation. Losses of DON and DOC are formulated using a new, extremely simple formulation, by which exudation rises with productivity as well as nutrient limitation. Further applications of this sub-module require verification with (mesocosm) data. More generally, future model versions need to address additional elementary pools like phosphorus, silicon or iron and energy or carbon, respectively demanding functions such as defense or storage. Given the generic nature of the adaptation dynamics of physiological traits proposed here, such extensions will be relatively straightforward.

Acknowledgements. M. Schartau and 4 anonymous reviewers gave helpful comments on the manuscript. T. Chapman (ScienceDocs, Inc.) improved grammar and style. R. Geider and N. Leonardos provided digital data from their experiments and supplementary information.

\section{LITERATURE CITED}

Abrams P (1999) The adaptive dynamics of consumer choice. Am Nat 153:83-97

Ågren G (1996) Nitrogen productivity or photosynthesis minus respiration to calculate plant growth? Oikos 76: 529-535

Anderson T (2005) Plankton functional type modelling: running before we can walk? J Plankton Res 27:1073-1081 Anning T, MacIntyre H, Pratt S, Sammes P, Gibb S, Geider R 
(2000) Photoacclimation in the marine diatom Skeletonema costatum. Limnol Oceanogr 45:1807-1817

Armstrong R (2006) Optimality-based modeling of nitrogen allocation and photoacclimation in photosynthesis. DeepSea Res II 53:513-531

Berges J, Charlebois D, Mauzerall D, Falkowski P (1996) Differential effects of nitrogen limitation on photosynthetic efficiency of photosystems I and II in microalgae. Plant Physiol 110:689-696

Cloern J, Grenz C, Vidergar-Lucas L (1995) An empirical model of the phytoplankton chlorophyll:carbon ratio: the conversion factor between productivity and growth rate. Limnol Oceanogr 40:1313-1321

Descy J, Leporcq B, Viroux L, Francois C, Servais P (2002) Phytoplankton production, exudation and bacterial reassimilation in the River Meuse (Belgium). J Plankton Res 24:161-166

Dortch Q, Clayton J, Thoresen S, Ahmed S (1984) Species differences in accumulation of nitrogen pools in phytoplankton. Mar Biol 81:237-250

> Droop M (1975) The nutrient status of algal cells in batch culture. J Mar Biol Assoc UK 55:541-555

Dubinsky Z, Falkowski P, Wyman K (1986) Light harvesting and utilization by phytoplankton. Plant Cell Physiol 27: 1335-1349

Elser J, Frost P, Kyle M, Urabe J, Andersen T (2002) Effects of light and nutrients on plankton stoichiometry and biomass in a P-limited lake. Hydrobiologia 481:101-112

Evans J, Terashima I (1987) Effects of nitrogen nutrition on electron transport components and photosynthesis in spinach. Aust J Plant Physiol 14:59-68

Falkowski P, Sukenik A, Herzig R (1989) Nitrogen limitation in Isochrysis galbana (Haptophyceae). II. Relative abundance of chloroplast protein D1. J Phycol 25:471-478

Finkel Z (2001) Light absorption and size scaling of lightlimited metabolism in marine diatoms. Limnol Oceanogr 46:86-94

Finkel ZV, Irwin AJ, Schofield O (2004) Resource limitation alters the $3 / 4$ size scaling of metabolic rates in phytoplankton. Mar Ecol Prog Ser 273:269-279

> Flynn KJ (2003) Modelling multi-nutrient interactions in phytoplankton; balancing simplicity and realism. Prog Oceanogr 56:249-297

Flynn K, Davidson K, Leftley J (1994) Carbon-nitrogen relations at whole-cell and free-amino-acid levels during batch growth of Isochrysis galbana (Prymnesiophyceae) under conditions of alternating light and dark. Mar Biol 118:229-237

Flynn KJ, Marshall H, Geider RJ (2001) A comparison of two $\mathrm{N}$-irradiance interaction models of phytoplankton growth. Limnol Oceanogr 46:1794-1802

Friend AD (1991) Use of a model of photosynthesis and leaf microenvironment to predict optimal stomatal conductance and leaf nitrogen partitioning. Plant Cell Environ 14:895-905

Fussmann GF, Ellner SP, Hairston NG Jr (2003) Evolution as a critical component of plankton dynamics. Proc R Soc B Biol Sci 270:1015-1022

Geider R, La Roche J (2002) Redfield revisited: variability of $\mathrm{C}: \mathrm{N}: \mathrm{P}$ in marine microalgae and its biochemical basis. Eur J Phycol 37:1-17

> Geider RJ, La Roche J, Greene RM, Olaizola M (1993) Response of the photosynthetic apparatus of Phaeodactylum Tricornutum (Bacillariophyceae) to nitrate, phosphate, or iron starvation. J Phycol 29:755-766

Geider RJ, MacIntyre H, Kana T (1998a) A dynamic regulatory model of phytoplanktonic acclimation to light, nutri- ents, and temperature. Limnol Oceanogr 43:679-694

> Geider RJ, Macintyre HL, Graziano LM, McKay RML (1998b) Responses of the photosynthetic apparatus of Dunaliella tertiolecta (Chlorophyceae) to nitrogen and phosphorus limitation. Eur J Phycol 33:315-332

Goericke R, Montoya JP (1998) Estimating the contribution of microalgal taxa to chlorophyll $a$ in the field - variations of pigment ratios under nutrient- and light-limited growth. Mar Ecol Prog Ser 169:97-112

Goldman JC (1988) Spatial and temporal discontinuities of biological processes in pelagic surface waters. In: Rothschild B (ed) Towards a theory on biological-physical interaction in the world ocean. Kluwer, Dordrecht, p 273-296

Goldman J, Glibert P (1982) Comparative rapid ammonium uptake by 4 species of marine phytoplankton. Limnol Oceanogr 27:814-827

Guglielmi G, Lavaud J, Rousseau B, Etienne AL, Houmard J, Ruban AV (2005) The light-harvesting antenna of the diatom Phaeodactylum tricornutum: evidence for a diadinoxanthin-binding sub-complex. FEBS J 272:4339-4348

$>$ Han B, Virtanen M, Koponen J, Straskraba M (2000) Effect of photoinhibition on algal photosynthesis: a dynamic model. J Plankton Res 22:865-885

> Herzig R, Falkowski P (1989) Nitrogen limitation in Isochrysis galbana (haptophyceae). I. Photosynthetic energy concersion and growth efficiencies. J Phycol 25:462-471

Hilbert DW (1990) Optimization of plant root/shoot ratios and internal nitrogen concentration. Ann Bot (Lond) 66:91-99

Hollinger DY (1996) Optimality and nitrogen allocation in a tree canopy. Tree Physiol 16:627-634

Klausmeier C, Litchman E, Levin S (2004) Phytoplankton growth and stoichiometry under multiple nutrient limitation. Limnol Oceanogr 49:1463-1470

Laws E, Bannister T (1980) Nutrient- and light-limited growth of Thalassiosira fluviatilis in continuous culture, with implications for phytoplankton growth in the ocean. Limnol Oceanogr 25:457-473

> Laws E, Wong D (1978) Studies of carbon and nitrogen metabolism by 3 marine phytoplankton species in nitratelimited continuous culture. J Phycol 14:406-416

Litchman E, Klausmeier C (2008) Trait-based community ecology of phytoplankton. Annu Rev Ecol Evol Syst 39: 615-639

Litchman E, Klausmeier C, Miller J, Schofield O, Falkowski P (2006) Multi-nutrient, multi-group model of present and future oceanic phytoplankton communities. Biogeosciences 3:585-606

Marra J (1978) Effect of short-term variations in light intensity on photosynthesis of a marine phytoplankter: a laboratory simulation study. Mar Biol 46:191-202

Marshall H, Geider R, Flynn K (2000) A mechanistic model of photoinhibition. New Phytol 145:347-359

McGill BJ, Enquist BJ, Weiher E, Westoby M (2006) Rebuilding community ecology from functional traits. Trends Ecol Evol 21:178-185

Morel F (1987) Kinetics of nutrient uptake and growth in phytoplankton. J Phycol 23:137-150

Pahlow M (2005) Linking chlorophyll-nutrient dynamics to the Redfield N:C ratio with a model of optimal phytoplankton growth. Mar Ecol Prog Ser 287:33-43

Parslow J, Harrison P, Thompson P (1984) Saturated uptake kinetics: transient response of the marine diatom Thalassiosira pseudonana to ammonium, nitrate, silicate or phosphate starvation. Mar Biol 83:51-59

> Prézelin B, Tilzer M, Schofield O, Haese C (1991) The control of the production process of phytoplankton by the physical 
structure of the aquatic environment with special reference to its optical properties. Aquat Sci 53:136-186

Raven J, Geider R (2003) Adaptation, acclimation and regulation in algal photosynthesis. In: Larkum AW, Douglas SE, Raven JA (eds) Photosynthesis in algae. Kluwer, Dordrecht, p 385-409

Rhiel E, Krupinska K, Wehrmeyer W (1986) Effects of nitrogen starvation on the function and organization of the photosynthetic membranes in Cryptomonas maculata (Cryptophyceae). Phys Lett 169:361-369

Richardson K, Beardall J, Raven J (1983) Adaptation of unicellular algae to irradiance: an analysis of strategies. New Phytol 93:157-191

Sakshaug E, Andresen K, Kiefer D (1989) A steady state description of growth and light absorption in the marine planktonic diatom Skeletonema costatum. Limnol Oceanogr 34:198-205

Schartau M, Engel A, Schröter J, Thoms S, Völker C, WolfGladrow D (2007) Modelling carbon overconsumption and the formation of extracellular particulate organic carbon. Biogeosciences 4:433-454

Sciandra A, Gostan J, Collos Y, Descolas-Gros C and others (1997) Growth-compensating phenomena in continuous cultures of Dunaliella tertiolecta limited simultaneously by light and nitrate. Limnol Oceanogr 42:1325-1339

Six C, Finkel Z, Rodriguez F, Marie D, Partensky F, Campbell D (2008) Contrasting photoacclimation costs in ecotypes of the marine eukaryotic picoplankter Ostreococcus. Limnol Oceanogr 53:255-265

Smith S, Yamanaka Y (2007) Quantitative comparison of photoacclimation models for marine phytoplankton. Ecol Model 201:547-552

Suggett DJ, Le Floc'H E, Harris GN, Leonardos N, Geider RJ (2007) Different strategies of photoacclimation by two strains of Emiliania huxleyi (Haptophyta). J Phycol 43: $1209-1222$
Sukenik A, Bennett J, Falkowski P (1987) Light-saturated photosynthesis. limitation by electron transport or carbon fixation? Biochim Biophys Acta 891:205-215

Sukenik A, Bennett J, Falkowski P (1988) Changes in the abundance of individual apoproteins of light-harvesting chlorophyll $a / b$ complexes of photosystem I and II with growth irradiance in the marine chlorophyte Dunaliella tertiolecta. Biochim Biophys Acta 932:206-215

Suzuki R, Fujita Y (1986) Chlorophyll decomposition in Skeletonema costatum: a problem in chlorophyll determination of water samples. Mar Ecol Prog Ser 28:81-85

Tang KW, Dam HG (2001) Phytoplankton inhibition of copepod egg hatching: test of an exudate hypothesis. Mar Ecol Prog Ser 209:197-202

Walters RG (2005) Towards an understanding of photosynthetic acclimation. J Exp Bot 56:435-447

Wilhelm C, Büchel C, Fisahn J, Goss R and others (2006) The regulation of carbon and nutrient assimilation in diatoms is significantly different from green algae. Protist 157: 91-124

Wirtz KW (2000) Simulating the dynamics of leaf physiology and morphology with an extended optimality approach. Ann Bot (Lond) 86:753-764

Wirtz KW (2002) A generic model for changes in microbial kinetic coefficients. J Biotechnol 97:147-162

Wirtz KW (2003) Adaptive significance of C partitioning and SLA regulation in Betula pendula. Tree Physiol 23: 181-190

> Wirtz KW, Eckhardt B (1996) Effective variables in ecosystem models with an application to phytoplankton succession. Ecol Model 92:33-53

Zlotnik I, Dubinsky Z (1989) The effect of light and temperature on DOC excretion by phytoplankton. Limnol Oceanogr 34:831-839

Zonneveld C (1998) A cell-based model for the chlorophyll a to carbon ratio in phytoplankton. Ecol Model 113:55-70

\section{Appendix 1.}

Photoinhibition. The photoinhibition term $u$ is understood here as the relative concentration of undamaged D1 proteins (Marra 1978). Han et al. (2000) proposed an evolution equation for $u$ using the D1 damage rate $k_{\mathrm{d}}$ and recovery rate $k_{\mathrm{r}}$. Compared to other regulatory processes resolved by our model, the resulting D1 evolution is very fast so that we refer to the equilibrium solution for $u$ (Han et al. 2000).

$$
u=k_{\mathrm{r}} / k_{\mathrm{r}}+k_{\mathrm{d}}
$$

Han et al. (2000) as well as Marshall et al. (2000) suggested that protein recovery rate $k_{\mathrm{r}}$ should increase with higher $\mathrm{N}$ : $\mathrm{C}$ ratio. In a simplified form this reads:

$$
k_{\mathrm{r}}=\mu_{\mathrm{d}} q
$$

It is reasonable that both the recovery and damage rate scale with $\mu_{\mathrm{d}}$. The damage rate $k_{\mathrm{d}}$ is introduced as a quadratic function of the chl a:C ratio $\left(=f_{\theta} \theta_{\mathrm{C}}\right)$, since pigment concentration affects the specific decay of D1 in many ways. The chl a:C ratio is related to the physical cross section of the 2 photosystems in which the sensitivity to photodamage rises. In addition, the ratio of photoprotective versus accessory pigments increases with nutrient limitation (Berges et al. 1996), which is accompanied by a low chl a:C ratio. An analogous negative correlation between photoprotective pigments and the chl a:C ratio was observed by Anning et al. (2000) in the light shift experiment.

$$
k_{\mathrm{d}}=k_{\mathrm{d}}^{\prime} \mu_{\mathrm{d}}\left(f_{\theta} \theta_{\mathrm{C}}\right)^{2} I
$$

Due to the functional dependency of $k_{\mathrm{d}}$ on state variables, the growth derivatives $\partial \mu / \partial X$ must be completed by adding $(\partial \mu / \partial u) \cdot(\partial u / \partial X)$ with $X=\theta, f_{\mathrm{R}}$ and $Q$.

Exudation and DIN source. Using inverse modeling techniques, Schartau et al. (2007) identified 2 different modes of dissolved organic carbon (DOC) exudation by algal cells. Under nutrient-replete conditions, exudation rate $L$ is proportional to production as is also evident from a series of studies (Descy et al. 2002, Elser et al. 2002, Zlotnik \& Dubinsky 1989). Under nutrient limitation, however, production ceases, but not exudation (apart from changes in DON quality). Here, we merge both modes into a single model formulation

$$
L=\frac{\eta}{f_{\mathrm{R}} q} P
$$

Release of exopolymers relative to total production is enhanced when $\mathrm{N}: \mathrm{C}$ ratio and chloroplast size (estimated by $f_{\mathrm{R}}$ ) decline. Analogously, lower growth irradiance induces a decrease in $f_{\mathrm{R}}$ (cf. Fig. 7) and, therefore, a rise in relative exudation rate, in accordance with observations of Zlotnik \& Dubinsky (1989). 
In the chemostat experiments (Thalassiosira fluviatilis) and the semi-continuous Skeletonema costatum batch culture of Anning et al. (2000) (with daily manual dilution), DIN is replenished by inflowing reservoir water at rate $D$. In the corresponding model configuration, the term (DIN $\left.{ }^{0}-\mathrm{DIN}\right) D$ is added to Eq. (2) and $-D P O C$ to Eq. (1), while all other equations remain unchanged.

Chl dynamics: smoothing and analysis. The simulation of Skeletonema costatum responding to shifting light levels is adapted to hourly stoichiometric changes. The chl $a$ :C ratio may then decrease faster than is possible by mere dilution due to growth. Even though $S$. costatum is known to express the chl a decomposing enzyme chlorophyllase (Suzuki \& Fujita 1986), too abrupt fluctuations are found to be unrealistic. We thus imposed in all case studies 2 additional constraints, which smooth chloroplast and chlorophyll decomposition: $\mathrm{d} f_{\mathrm{R}} / \mathrm{d} t \geq-P \cdot f_{R}$ and $\mathrm{d} \theta / \mathrm{d} t \geq$ $-\left(P+f_{\mathrm{R}}^{-1} \cdot \mathrm{d} f_{\mathrm{R}} / \mathrm{d} t+\sigma q^{-1} \cdot \mathrm{d} q / \mathrm{d} t\right) \theta$ (equivalent to dchl $a / \mathrm{d} t>$ $0)$.

In order to quantify the model contributions underlying the optimization of chlorophyll levels, we define the control indices of chl a:C ratio dynamics.

$$
\begin{aligned}
& (\mathrm{Chl}: \mathrm{C})^{-1} \frac{\mathrm{d}(\mathrm{chl} a: \mathrm{C})}{\mathrm{d} t}= \\
& \sum_{i=1}^{5} g_{i} \underbrace{\frac{\delta_{\mathrm{R}}}{f_{\mathrm{R}}} \frac{\partial \mu}{\partial f_{\mathrm{R}}}}_{g_{1}}+\underbrace{\frac{\delta_{\mathrm{R}}}{f_{\mathrm{R}}} \frac{\partial \mu}{\partial Q} \frac{\mathrm{d} Q}{\mathrm{~d} f_{\mathrm{R}}}}_{g_{2}}+\underbrace{\frac{\delta_{\theta}}{\theta} \frac{\partial \mu}{\partial \theta}}_{g_{3}}+\underbrace{\frac{\delta_{\theta}}{\theta} \frac{\partial \mu}{\partial Q} \frac{\mathrm{d} Q}{\mathrm{~d} \theta}}_{g_{4}}+\underbrace{\frac{\sigma}{Q-Q_{0}} \frac{\mathrm{d} Q}{\mathrm{~d} t}}_{g_{5}}
\end{aligned}
$$

Formally, the partial derivatives of $\mu$ resemble derivatives of a potential function, which describe forces acting in a physical system. Here, the optimality seeking a 'force' changing chl a:C ratio is split into different contributions stemming from variations of the 3 factors $f_{\mathrm{R}}, \theta$ and $q^{\sigma}$ that together make the chl a:C ratio. The force terms $g_{1}$ and $g_{2}$ are attributed to the differential benefits and costs of building up Rubisco, while $g_{3}$ and $g_{4}$ are related to the synthesis of LHC (note that changes in $f_{\mathrm{R}}$ due to $g_{1}$ and $g_{2}$ contribute equally to variations in $f_{\theta}$, but are treated here separately). For smoothing out sharp transitions between day and night periods, relative control indices are defined as half-day time averages $(\Delta t=0.5 \mathrm{~d})$ of the normalized forces:

$$
\widetilde{g_{j}}(t)=\Delta t^{-1} \int_{t-\Delta t / 2}^{t+\Delta t / 2} \frac{\left|g_{j}\right|}{\sum_{i=1}^{5}\left|g_{i}\right|}
$$

Editorial responsibility: Otto Kinne, Oldendorf/Luhe, Germany
Submitted: December 1, 2008; Accepted: September 21, 2009 Proofs received from author(s): February 8, 2010 